\title{
sciendo
}

\section{Descriptive Rules and Normativity}

\author{
Adriana Placani \\ University of Graz, Austria \\ DOI: $10.2478 /$ disp-2020-0007 \\ BIBLID [0873-626X (2020) 57; pp.167-180]
}

\begin{abstract}
This work offers a challenge to the orthodox view that descriptive rules are non-normative and passive in their role and usage. It does so by arguing that, although lacking in normativity themselves, descriptive rules can be sources of normativity by way of the normative attitudes that can develop around them. That is, although descriptive rules typically depict how things are, they can also play a role in how things ought to be. In this way, the limited role that this type of rule can play as either a basis for the development of normative reasons, or as explanatory reasons for action is identified and clarified. One desirable outcome of the analysis is a more complete view of what descriptive rules are and how they are utilized by agents.
\end{abstract}

\section{Keywords}

Descriptive rules, normativity, expectations, rules, reasons.

\section{Introduction}

The variety of rules that confront us every day is undeniably great. One way of making sense of this abundance is to distinguish between rule types. However, the grounds on which such differentiations can be made are themselves rich in complexities. One strategy is to distinguish between types of rules on the basis of their varying capacities for guiding subjects, their uses or aims. To some degree, the following work takes into account all of these bases in order to explore the nature of descriptive rules and provide a clearer view of their meaning, use and role.

Provisionally, descriptive rules can be defined as rules that state an empirical regularity or a generalization (Von Wright 1963; Schauer 1991:1). The standard conception holds that this rule type is used to reflect and describe the world rather than apply pressure to it 
(Schauer 1991: 2). From the get-go, then, it appears that descriptive rules lack guiding power. This is perhaps striking if only because normativity seems intimately linked to the concept of a rule itself.

Determining whether in all cases descriptive rules are non-normative requires both deeper analysis and comprehensive accounting of the full range of their traits and applications. As such, the first aim of this work is to define descriptive rules in a more comprehensive manner. Not only will this help to broaden the conceptual boundaries of descriptive rules, but it will also serve as the basis for an examination of the relationships between these kinds of rules and normativity. As will be shown with greater refinement, descriptive rules impact the world in a different way than other rules, such as constitutive, regulative, or prescriptive rules. While guiding force is not a constant feature of descriptive rules, it can be a consequence of their existence. In other words, under certain circumstances, descriptive rules can factor into the balance of reasons of agents in a limited way.

The structure of this work is as follows. Section one contends with the definition and analysis of descriptive rules. In this, it not only reconstructs the classic interpretation of these rules, but also examines the contrasts between descriptive rules and other types. Section two narrows focus to the relationships between normativity and descriptive rules. It addresses these through the extensive use and development of a hypothetical, which helps to draw out the ways in which descriptive rules can enter into an agent's balance of reasons. Section three concludes this work.

\section{Exploring the contours of description}

As stated before, descriptive rules can be provisionally defined as rules that state an empirical regularity or a generalization (Schauer 1991: 1). They are often contrasted with prescriptive rules. Whereas descriptive rules state how the world is, prescriptive rules state how the world ought to be. In that, descriptive rules seem to lack any kind of normativity; they simply mirror or reflect a state of affairs (Schauer 1991: 2). The latter statement may prove less stark by the end of this essay, but for now focusing on the archetypal usage of descriptive rules should clarify this rule type and distinguish it from the general array of rules. 
Different statements can be categorized as descriptive rules and still accord with the above provisional definition. Laws of nature fit under the rubric, but so do habits, generalizations and stereotypes. Some examples of the first sort are Newton's law of gravitation; Newton's laws of motion; 'planets within this solar system follow elliptical trajectories'; '(All pure) copper conducts electricity'. ${ }^{1}$ Representative usages of the latter sort are: "As a rule, Mexican food is spicy"; Paul smokes two packs of cigarettes a day; and, "As a rule, it snows in December in Budapest" (Ibid). The distinctive trait of all descriptive rules is their reflective or mirroring capacity of regularities. As such, the empirical repetition described by these rules falls on a continuum that comfortably includes social and personal practices, as well as universal laws.

The above can be expanded in order to better isolate the general characteristics that are constitutive of descriptive rules. Descriptive rules appear to display the following general traits: (1) they are empirically verifiable; and, (2) they are either true or false (von Wright 1958: 12). These two substantive traits stand to unify all descriptive rules. However, some descriptive rules do not have the character of being true in perpetuity. The truth stated by a law of nature is unvarying or constant. This compares with a rule about personal or social habits, which might exhibit a higher degree of changeability. Furthermore, the necessary truth of certain laws contrasts with the contingent truth of others (Ibid:15). Thus, although descriptive rules can stand united in principle by displaying the two characteristics above important differences among them remain.

The two traits of descriptive rules listed can be sharpened through contrast with some other rule types. While the truth value of descriptive rules functions as a means of determining their worth or utility for a user, regulative and (the sub-type) prescriptive rules depend on justification. ${ }^{2}$ To illustrate consider some examples of prescriptive rules: "Thou shalt not steal", "No vehicles in the park" or "During sleep hours you ought to keep quiet". These rules contain

${ }^{1}$ For more on laws of nature, see: Armstrong 1983, Cartwright 1983, Dretske 1977, Earman 1978, Popper 1959, Ramsey 1978, Strawson 1989, Swoyer 1982, Tooley 1977.

${ }^{2}$ Briefly, I take prescriptive rules to be a sub-type of the larger regulative category. The difference is that prescriptive rules have a clear issuing source. 
normative semantic content and possess normative force (Schauer 1991: 1). They are used to guide, control, or change the behavior of agents with decision-making capacities (Ibid.). Consequently, prescriptive rules are not truth-apt, meaning that they do not possess truth-value (von Wright 1963).

In contrast, descriptive rule are typically devoid of such normative content. As descriptive statements they communicate that something "is" the case. Consequently, verifiability is the appropriate test for their (potential) continual existence, with truth and falsehood as possible results. This works in the following way. Descriptive rules capture an empirical regularity, but they neither normatively specify it nor causally determine it. Thus, the descriptive rule stating that 'the sun sets in the west and rises in the east' (quite obviously) does not control or affect the regular action itself. The rule describes the regularity and does not attempt to change, guide, or otherwise control the action, behavior or other ordering depicted therein. That which is verifiable with respect to descriptive rules, then, is the regularity that they identify, which within the bounds of the rules lacks any normatively-charged feature or function.

From the above, another trait can be identified; namely, patterns exist prior to their formalization in descriptive rule form. This matter of temporal sequence sets descriptive rules apart from the constitutive rule type. Whereas constitutive rules give rise and establish new forms of behavior (Placani 2017; Searle 1969), descriptive rules portray regularities that already exist. So, prior to there being a regularity a descriptive rule cannot be formulated. When the regularity ceases the rule should be abandoned as it has no use (other than perhaps a heuristic function). Consequently, regularities captured by descriptive rules are logically prior to the rules themselves.

The apparent absence of normativity along with the truth value of descriptive rules results in their inviolability. Since a descriptive rule is either true or false, then any deviation from its content is either an exception to the rule or proof that the rule is mistaken. As non-normative statements, descriptive rules do not benefit from the possibility of contravention. In this sense, they do not arrange a state of affairs in a manner distinct from their factual content. However, if such content proves to be erroneous or false, then their status as descriptive rules falters. Consider the sample descriptive rule that 
"most kittens enjoy milk". The example provides a generalization about most kittens' enjoyment of milk. Some kittens do not enjoy milk, which proves to be an exception to the rule. If exceptions are allowed by the rule's formulation then these do not, on their own, jeopardize its truthfulness.

Without the provision for exceptions, any rule so formulated can be falsified by counterexamples or verification demonstrating otherwise. Take, then, the rule that "the sun revolves around the earth". This was most famously proven false. Note that regularities which are incongruous with the rule's content do not violate the rule, because the rule is not the reason for the regularity. This brings us into normative realms. It has been noted that descriptive rules do not state how things ought to be, but rather how they are. In other words, descriptive rules do not provide normative reasons for action; they lack normative force. ${ }^{3}$ As such, they cannot enter into practical reasoning about what action ought to be taken and cannot be violated. This again contrasts with the case of regulative or prescriptive rules whose aim of guiding action creates myriad avenues for violation.

The preceding paragraphs have identified the core, common characteristics of descriptive rules. This account remains whetted to standard depictions of such rules, which come from Von Wright, Hare, as well as Schauer. In spite of the traits treated above, there remains a central issue about descriptive rules that has yet to be addressed; namely, whether their apparent lack of normative force holds in all cases. This matter motivates the next section.

\section{Normativity and description}

This section more thoroughly investigates the relationships between descriptive rules and normativity. As discussed above, the standard depiction of these rules shows that they do not exert normative force. However correct, descriptive rules can contribute to the creation of

\footnotetext{
${ }^{3}$ Another aspect of descriptive rules, pointing to their lack of normative force, is an absence of evaluative meaning. Descriptive rules are not evaluative in the sense that they do not point to anything good in their content. Nevertheless, 'good' can be descriptive. However, the descriptive meaning of 'good' is secondary to its evaluative meaning. For a discussion of this see: Hare 1952.
} 
normative reasons for action, and potentially to the development of regulative and prescriptive rules. In this respect, a more complete picture of rules can acknowledge the broader developmental role that the descriptive type can play. While they formalize preexisting regularities, they also have the potential to lead to normative attitudes because and in virtue of the rules themselves. It is the second clause of the preceding sentence that will be at issue in the following section. As such, the analysis below identifies a way in which the rules can lead to and establish expectations that then engage (normative) claims about what agents ought to do (or refrain from doing).

Consider a hypothetical where agents engaged in practices that can be formulated by way of descriptive rules become grounds for normative claims about the actions and attitudes of the agents. Three friends, Kenny, Johnnie, and Rosie, meet every Sunday for a movie night. As a rule, Kenny purchases the movie tickets, Johnnie buys treats at the cinema snack bar, and Rosie buys drinks for all of them afterwards. Suppose that Kenny, Johnnie and Rosie did not explicitly decide on or agree to the arrangement that the rule identifies. ${ }^{4}$ Things started in this manner and simply continued in the same way. ${ }^{5}$

The preceding describes a regular event and set of actions for these three agents. The regularity of behavior observed is captured by way of a descriptive rule. Regarding Kenny, the descriptive rule might take the form of: "As a rule, Kenny buys movie tickets every Sunday". His behavior exhibits a regularity that has been acquired over time. This might not look as tidy as the laws of motion, but it nevertheless qualifies as an example of a descriptive rule that reflects the friends' system for contributing to movie nights and conforms to the standard definition already set out.

\footnotetext{
${ }^{4}$ This is an important note because had the friends decided on these matters, their decision would have counted as a personal rule.

${ }^{5}$ Questions might still linger as to whether the statement "as a rule, Kenny purchases movie tickets for his friends (...)" can be properly thought of as a descriptive rule. Notice that it conforms to the definition and conception of descriptive rules above. Again, descriptive rules are used to state an empirical regularity or generalization (Schauer 1991:1). The statement about Kenny and his friends describes or reflects just such an empirical regularity. That which is specific to this rule is the agential component. This is a descriptive rule that generalizes some of Kenny's actions.
} 
One of the ways of determining the nature of any rule is by attempting to depart from its stated content. The attempt of an agent to depart from a rule can be conscious, when the agent knows that a rule exists, or unconscious, when the agent does not know that a rule is in place. In the latter case, the agent can become aware of the rule's existence due to the resistance that she is likely to face upon attempting to act in a way that is different from the rule's stipulations. Take a departure from the rule associated with Kenny and his friends: Before going to movies with his pals, Kenny calls Rosie and asks if he should purchase the tickets. Rosie is mystified, and wonders why Kenny would ask this since he always buys the tickets. In response to his query, Rosie says: "Well, you've always been the one to buy the tickets so I assumed you had already purchased them. Is something wrong?"

One can see why Rosie may be confused in this case. Her expectation is that Kenny has already purchased the tickets - an action consistent with his past conduct - yet there is nothing in the descriptive rule itself that entails any reason for Kenny to purchase tickets. The rule does not, on its face, indicate even the more minimal claim that he should buy the tickets. Still, Kenny has always bought the movie tickets, and this regularity might serve to ground normative claims about his actions and their continued performance. The regularity of Kenny's actions is now taken by his friends as an indication that Kenny will continue to follow the same pattern. The fact of Kenny's habitual actions gives his friends a reason to believe that the pattern will persist just like it has. To be sure, this speaks of patterns generally and not of Kenny's friends in particular.

Patterns of behavior or simply repeated acts tend towards normalization, routinization, and establishment as status quo. Uncertainty or confusion when the status quo is altered or questioned, as when Kenny asked Rosie about buying tickets, indicates the potential for normative attitudes vis-à-vis descriptive rules. Rosie's normative attitude is rooted in the belief that the pattern, captured by the descriptive rule, will continue. This gives rise to expectations about Kenny's future actions on her part. Furthermore, Rosie relies on those expectations when making her own decisions and plans. It should be noted that the example is merely set up in this fashion, but the assumptions that underpin it are reasonable. 
At this point a seemingly peculiar question can be posed; namely, should Kenny continue to purchase movie tickets because his friends have come to rely on him doing so? The peculiarity is that, thus far, Kenny and his friends have merely acted with such regularity that the pattern can be formalized by way of a descriptive rule. Nevertheless, acting with such regularity has, per the example, spawned expectations on the part of Kenny's friends. These expectations have impacted the treatment and consideration that Rosie and Johnnie give to movie night, and the respective fixity of the friends' roles in making it happen without problems. The question above, then, interrogates the core trait of descriptive rules - their non-normativity. It asks whether because of expectations surrounding it, the descriptive rule has come to carry normative weight or force.

Before answering the above question directly, it is necessary to address at least briefly some tangential, substantive problems. The first problem pertains to the difference between the descriptive rule and the empirical regularity it captures. On its face, it looks like the problem resolves itself as soon as the conditions for definition are remembered. The pattern reflected by the rule predates the rule, and as such it is requisite for the rule's formation. The formation of the rule as a representation of the verifiable regularity marks a difference between it and that which it formalizes. Nonetheless, formalization alone does not capture every significant aspect of the content that descriptive rules respectively reflect. Descriptive rules can, in certain cases, add to the content that they capture.

For instance, descriptive rules may add to the content that they reflect their own status as rules. This may seem a bit ambiguous, but the idea behind it relies on what has already been established. If an empirical regularity is recognized as a rule then the regularity is formalized. The status as rule lends more weight to an observed or verified regularity that is now recognized as such. To see how this works, consider that in some cases people may no longer feel that it is needed to verify that a rule's content is correct. If a rule about a pattern is established then it is natural to assume that that pattern is true. This, of course, may not always be the case as some descriptive rules will capture content that is true only contingently. Nevertheless, this can explain why some descriptive rules may stay in place longer than the regularity that they seek to reflect. 
To return to the example, the descriptive rule: "As a rule, Kenny buys movie tickets for his friends" states an empirical regularity in Kenny's behavior. The rule cannot exist independently of Kenny's actions. When normative attitudes about this descriptive rule come into the fore and result in expectations (in this case, the expectations of people with whom Kenny stands in special relationships), one could think that these expectations are not about the rule itself, but merely about its content, which reports on Kenny's actions. However, such expectations typically arise when an observed empirical regularity can be formalized by way of a descriptive rule, in other words, when the pattern has gained the status of rule.

The fact that the empirical regularity in Kenny's behavior has been recognized as a rule can give rise to reasonable expectations on the part of Kenny's friends that this regularity will persist. Both the rule and the expectations which surround it contribute to why it is that Kenny may now have a new reason to buy movie tickets for movie night. The expectations regarding Kenny's actions are based on the fact that there is a rule about his actions. In this way, due to the fact that Kenny's repeated actions in the past can be formalized by way of a descriptive rule it is possible for his friends to infer that in the future he will continue to act similarly and on this basis expect that he will do just that. The descriptive rule as detailed can in this sense be verified by observing Kenny habitual action of buying the movie tickets.

The existence of a descriptive rule and the reasonable expectations of people with whom Kenny stands in a special relationship, are apt to give Kenny a normative reason to go along with the pattern. Rosie and Johnnie have come to rely on their pal continuing to do as he has in the past. ${ }^{6}$ They have grounds to criticize Kenny or demand that he make amends if he fails to meet their expectations. ${ }^{7}$ Kenny

${ }^{6}$ This need not be the case. The hypothetical explores the possibility that reasonable expectations develop in order to explore relations between descriptive rules and normative reasons for action.

${ }^{7}$ The sort of criticism at stake is a blaming response, reprimand, reproach or indignation for the failure to meet one's reasonable expectations. These kinds of attitudes are part of the repertoire of reactive attitudes. See: Strawson 1962. Thank you to an anonymous reviewer for pointing out the need to clarify this. 
may not have realized that this would happen, but upon attempting to act differently from the descriptive rule he has encountered resistance and pressure. It is true, however, that not all expectations will give rise to normative demands, but that legitimate expectations will.

If expectations are legitimate, then they will bear the hallmark of normativity. Following Brown (2017), legitimate expectations entail three principal features: they are predictive (i.e., partially constituted by beliefs about the future); they are prescriptive (i.e., they entail beliefs about what the future should be) and justifiable (i.e., agents have an epistemic warrant or justification for holding such beliefs). It is not for this paper to determine under what conditions an expectation counts as a legitimate one. What suffices for the purposes of this essay is the claim that the existence of descriptive rules can give rise to expectations and that some of these expectations will be legitimate.

When expectations are legitimate, they ground a normative reason for agents to conform to the expectation or make some form of amends for frustrating it. This may lead to further questions about who has the standing to hold others to account on the basis of such expectations. ${ }^{8}$ This is a difficult question, ${ }^{9}$ but one that need not halt our current pursuit. It is sufficient to note that some of the expectations that form around some descriptive rules will be held by agents who possess both legitimate grounds to form such expectations and to hold others to account for failing to meet them. In such cases, the descriptive rules can

${ }^{8}$ Thank you to the anonymous referee who pressed me on this point.

9 To illustrate the complexity of the matter, consider Simmons' (1981) example of Kant's famous walks through Konigsberg. Simmons argues that even though one may have a reasonable expectation that things follow the same pattern, one may not have the standing to criticize another for deviating from the pattern. In the Konigsberg example, it seems that Kant would not be to blame for failing to meet the expectations of locals regarding his daily walks if he decided to stay at home one day, in part, because he had not actively encouraged such expectations. There may be yet other reasons (e.g., lack of knowledge or negligent deceit). What is important to note is that it is not necessary for the limited purposes of this essay to be able to specify under what conditions someone can be justifiably criticized or blamed (and by whom) for failing to meet others' expectations. It suffices that such conditions can sometimes be met, which the Kenny example illustrates. 
constitute a basis for normative claims that the expectations be met or grounds for blaming responses if they are not met.

In the hypothetical offered, the expectations of Rosie and Johnnie give rise to a normative reason for Kenny not to deviate from the rule (i.e., fulfill their expectations) and ground a blaming response should Kenny fail to conform. This could be, in part, in virtue of the special nature of the relationship between the three. After all, Kenny's friends have an interest that he fulfill their legitimate expectations (i.e., they rely on the expectation being fulfilled) and Kenny is obligated to promote his friends' interests in ways that he is not obligated to promote others' interests. Kenny's normative landscape is altered because Kenny has a new normative reason to conform to the descriptive rule or pattern that he co-created in virtue of his friends' legitimate expectations that he does so. It should be noted, however, that it is beyond the ambitions of this paper to determine under what conditions people have valid claims that their expectations be fulfilled. Suffice it to say that such valid normative claims can exist. What is more such claims can arise because descriptive rules provide grounds for the formation of expectations.

In spite of these complications and complexities, it should be stressed that descriptive rules are not normative in themselves. They do not prescribe, allow, permit, or prohibit actions. However, when certain conditions are present (e.g., legitimate expectations), they can be the basis for or the background against which normative reasons for action are created. The example illustrates a case where normative attitudes developed around a descriptive rule. It bears mentioning that, in addition to the above, and in spite of the fact that descriptive rules cannot be reasons for action in and of themselves, this rule type can fulfill an explanatory function. Descriptive rules, such as habits, can be explanatory reasons for action for agents. What this means is that while the rules may not provide reasons that can justify action, they can sometimes explain it. Consider one illustration. The fact that Jane has a habit of smoking may explain her continuing to smoke, but it does not justify her doing so. The existence of a habit explains an action consistent with it, but, on its own, it is not a consideration in favor of it. A justifying reason would need to point to some good the action for which it is 
a reason would bring. ${ }^{10}$ Consequently, the role of descriptive rules remains limited as compared to other rules which factor prominently in the balance of reasons of agents. Nevertheless, these rules can help make sense of our world.

\section{Conclusion}

The preceding firstly defined descriptive rules in line with standard accounts of this rule type. The definition and analysis provided in the first section conceptualized descriptive rules and contrasted them with other types. Descriptive rules were singularized, but also included in the variety of rules encountered by agents. The account presented descriptive rules as almost passive in their role and usage. Yet, this did not undermine their relevance. Verifiability and truth-aptness were identified as core traits of this rule type. The logical priority of empirical regularities helped distinguish descriptive from constitutive rules. On the other hand, the absence of normative content helped distinguish descriptive from regulative and prescriptive rules.

Section two explored through the use of an example the relationship between descriptive rules and normative reasons for action. The lack of normativity characteristic of descriptive rules remained firmly rooted, but normative attitudes developed around and from the rules. This showed that although descriptive rules typically depict how things are, they can also play a role in how things ought to be. The limited role that this type of rule can play as either a basis for the development of normative reasons, or as explanatory reasons for action was identified and clarified. One desirable outcome of this analysis is a more complete view of what descriptive rules are and how they are utilized.

${ }^{10}$ The simplest way of distinguishing between explanatory and justifying reasons is by resorting to evaluative considerations. In a nutshell, if there is nothing that points to the good in one's explanatory reason for X-ing then it does not count as a justifying reason in favor of X-ing. A normative justifying reason for action may also be explanatory, but an explanatory reason need not be normative. For much more on the distinction between explanatory and justifying reasons, see: Baier 1958, Dancy 2000, Darwall 2003, Davidson 1980, Korsgaard 1996, Parfit 1984, Scanlon 1998, Williams 1981. 
Adriana Placani

Institute of Philosophy

University of Graz, Austria

adriana.placani@uni-graz.at

\section{References}

Alexander, L. and Sherwin, E. 1994. The deceptive nature of rules. University of Pennsylvania Law Review 142(4): 1191-225.

Alexander, L. and Sherwin, E. 2001. The Rule of Rules: Morality, Rules, and the Dilemmas of Law. Duke University Press.

Armstrong, D. 1983. What is a Law of Nature? Cambridge: Cambridge University Press.

Audi, R. 2008. Belief, faith, and acceptance. International Journal for Philosophy of Religion 63(1/3): 87-102.

Baier, K. 1958. The Moral Point of View. Ithaca: Cornell University Press.

Black, M. 1962. Models and Metaphors. Cornell: Cornell University Press.

Broome, J. 2000. Normative requirements. In Normativity, ed. by Dancy, Jonathan. Blackwell, Oxford.

Brown, A. 2017. A theory of legitimate expectations. Journal of Political Philosophy 25(4): 435-60.

Bulygin, E. 1992. On norms of competence. Law and Philosophy 11: 201-16.

Cartwright, N. 1983. How the laws of physics lie. Oxford: Oxford University Press.

Dancy, J. 2000. Practical Reality. New York: Oxford University Press.

Darwall, S. 2003. Desires, reasons and causes. Philosophy and Phenomenological Research 67: 435-43.

Davidson, D. 1980. Actions, reasons and causes. In Essays on Actions and Events. Oxford: Clarendon Press.

Dretske, F. 1977. Laws of nature. Philosophy of Science 44: 248-68.

Earman, J. 1978. The universality of laws. Philosophy of Science 45: 173-81.

Finnis, J. 1980. Natural Law and Natural Rights. Oxford: Clarendon Press.

Flathman, R. 1973. Concepts in Social and Political Philosophy. New York: Macmillan Publishing Co., Inc.

Gilbert, M. 2006. A Theory of Political Obligation. Oxford: Clarendon Press.

Goldman, A. 1970. A Theory of Human Action. Englewood Cliffs: Prentice-Hall.

Hare, R. 1952. The Language of Morals. Oxford: Clarendon Press.

Hart, H. L. A. 1961. The Concept of Law (2nd Edition). Oxford: Oxford University Press.

Hart, H. L. A. 1982. Essays on Bentham. Oxford: Oxford University Press.

Korsgaard, C. 1996. The Sources of Normativity. Cambridge: Cambridge University Press.

McClennen, E. 2004. The rationality of being guided by rules. In The Oxford Handbook of Rationality ed. by A. Mele and P. Rawling. New York: Oxford University Press. 
McClennen, E. and Shapiro, S. 1998. Rule-guided behavior. In The New Palgrave Dictionary of Economics and the Law, ed. by Newman, Peter. New York: St Martin's Press.

Midgley, G. 1959. Linguistic rules. Proceedings of the Aristotelian Society LIX: 271-90.

Moore, G. E. 2004. Some Main Problems of Philosophy. Leicester: Blackfriars Press.

Parfit, D. 1984. Reasons and Persons. Oxford: Oxford University Press.

Placani, A. 2017. Constitutive and regulative rules: a dispute and a resolution. Phenomenology and Mind 13: 56-62.

Popper, K. 1959. The Logic of Scientific Discovery. New York: Basic Books.

Ramsey, F. 1978. Foundations. London: Routledge and Kegan Paul.

Rawls, J. 1955. Two concepts of rules. Philosophical Review 64: 3-32.

Ross, A. 1968. Directives and Norms. London: Routledge.

Scanlon, T. 1998. What We Owe to Each Other. Cambridge, MA: Harvard University Press.

Schauer, F. 1991. Playing by the Rules: A Philosophical Examination of Rule-Based Decision-Making in Law and in Life. Oxford: Clarendon Press.

Searle, J. 1969. Speech Acts: An Essay in the Philosophy of Language. Cambridge: Cambridge University Press.

Searle, J. 1995. The Construction of Social Reality. New York: The Free Press.

Searle, J. 1999. Mind, Language and Society. New York: Basic Books.

Simmons, A. J. 1981. Reasonable expectations and obligations: a reply to Postow. Southern Journal of Philosophy 19(1): 123-7.

Smith, B. 2003. John Searle: from speech acts to social reality. In John Searle, ed. by B. Smith. Cambridge: Cambridge University Press.

Strawson, G. 1989. The Secret Connexion: Causation, Realism, and David Hume. Oxford: Oxford University Press.

Strawson, P. F. 1962. Freedom and resentment. Proceedings of the British Academy 48: 1-25. Reprinted in Fischer and Ravizza 1993, 45-66.

Swoyer, C. 1982. The nature of natural laws. Australasian Journal of Philosophy 60: 203-23.

Tooley, M. 1977. The nature of laws. Canadian Journal of Philosophy 7: 667-98.

Ullman-Margalit, E. 1980. The Emergence of Norms. Oxford: Oxford University Press.

Velleman, D. 2000. The Possibility of Practical Reason. Oxford: Oxford University Press.

Von Wright, G. H. 1963. Norm and Action. London: Routledge and Kegan Paul. Williams, B. 1981. Internal and external reasons. Moral Luck. Cambridge: Cambridge University Press. 